\title{
EVALUATION OF APICAL EXTRUSION OF DEBRIS AND IRRIGANT USING TWO ROTARY INSTRUMENTATION SYSTEMS
}

\author{
Rasha M. El-Barkouky ${ }^{l *} B D S$, Sybel M. Moussa ${ }^{2} P h D$, Mohamed H. Mohy El-Din ${ }^{3} P h D$, \\ Nihal A. Leheta ${ }^{4} P h D$
}

\begin{abstract}
INTRODUCTION postoperative flare-ups. single file system and a multiple file rotary system. 0.05 . P-values less than 0.05 were considered significant. as compared with the use of the multiple-file system.

KEYWORDS: Debris, Instruments, Irrigant, Rotary.

\footnotetext{
1. $\quad$ B.D.S 2008.

2. Professor of Endodontics, Faculty of Dentistry, Alexandria University.

3. Professor of Dental Biomaterials, Faculty of Dentistry, Alexandria University.

4. Lecturer of Endodontics, Faculty of Dentistry, Alexandria University.
}

Apical extrusion of debris and irrigants during cleaning and shaping of the root canal is one of the main causes of peri-apical inflammation and

OBJECTIVES: The purpose of this study was to quantitatively measure the amount of debris and irrigants extruded apically using rotary

METHODOLOGY: Thirty extracted upper six molars were selected. In all teeth the distal roots were sectioned and shortened to a length of $15 \mathrm{~mm}$. The specimens were randomly divided into two groups $(\mathrm{n}=15)$ according to the instrumentation system used. Group A: One shape file (single file system), Group B: Revo-S (multiple-file rotary system). Bi-distilled water was used as the irrigant with traditional needle irrigation delivery system. The apically extruded debris and irrigant were collected into pre-weighed glass vials. The amount of extruded debris and irrigant were assessed with a precision electronic balance. The liquid inside the tubes was dried and the mean weight of debris was assessed. The data were statistically analysed using SPSSS IBM version 22. All statistical analysis was done using two tailed tests and alpha error of

RESULTS: The One shape file system produced significantly less amount of debris and irrigant compared with Revo-S file system. CONCLUSION: Although all systems caused apical extrusion of debris and irrigant, the single file system was associated with less extrusion

\section{INTRODUCTION}

Root canal preparation is an important step in endodontic treatment, and it plays a key role in treatment success. During chemo-mechanical preparation of root canals, necrotic debris, pulp remnants, microorganisms, dentin chips and irrigants can be extruded into the apical region. These substances can lead to inflammation, flare-ups or healing delays (1). Numerous studies have evaluated the extrusion of intracanal materials through the periapical region. A common finding has been that all instrumentation techniques produce apical extrusion of debris and irrigant to a certain extent (2-5).However, the amount of apical extrusion can vary according to the technique used $(4,5)$.

It is generally accepted that instrumentation techniques that incorporate rotational action generate less debris than push-pull instrumentation, and the crown-down technique has been associated with the least amount of debris extrusion, compared with techniques involving a linear filing motion. Thus, engine-driven rotary systems have tended to extrude less debris than hand techniques $(3,6)$.

Most nickel-titanium instruments using torque control devices work with different instrumentation techniques, such as rotational or reciprocal action. There are different designs available, with some having variations in flute depth, different tapers, or cross-sections and others having radial lands (1). Single-file nickel-titanium One Shape system, which can prepare the entire root canal with only one instrument, was recently introduced. In contrast the Revo-S file system prepares the entire canal using three instruments. To the best of our knowledge, although there have been similar studies in the literature, no studies have compared the extrusion of both apical debris and irrigation solution by rotary One shape single-file system and Revo-S multiple file system. The aim of this study was to evaluate the amount of apically extruded debris and irrigant using single-file systems, One Shape compared with the rotary full-sequence Revo-S.

\section{MATERIALS AND METHODS:}

Thirty extracted upper six molars with mature apices and curvature more than 10 and less than 25 degrees according to Schneider's technique were selected. The teeth were cleaned of external debris and soft-tissue remnants and were stored in $10 \%$ formalin solution. All of the teeth were $\mathrm{x}$ rayed preoperatively in buccal and proximal directions. Only teeth with mature apices and free from attrition were used. Teeth with calcification and root caries were extruded.

Thirty teeth were classified into two groups of fifteen each:

1. Group A: One shape files (Micro-Mega, Cedex, Besancon, France), size 25 at the tip and having a taper of 0.06 , was used according to the manufacturer's instructions with rotational motion.

2. Group B: Revo-S files (Micro-Mega, Cedex, Besancon, France), were used according to the manufacturer's instructions as follows: Sc1(0.006), $\mathrm{Sc} 2(0.004), \mathrm{SU}(0.006)$. 
To standardize the working length of the specimens, all of the teeth were shortened to $15 \mathrm{~mm}$ by an air motor handpiece and a diamond bur (Dentsply/Maillefer, Tulsa, USA). Two coats of nail varnish were applied to the external surface of the roots in order to prevent debris and irrigant extrusion through lateral canals. The working length of each tooth was determined by inserting a size $10 \mathrm{~K}$-file (Dentsply/Maillefer, Tulsa, USA) into the canal until the tip of the file was minimally visible at the apical foramen. The working length was then set as $1 \mathrm{~mm}$ less than that of the canal length.

In this study, an experimental model was used, as described by Mayers and Montgomery (7). Before starting the experiment the vials were weighted by a $10-4$ precision on an electronic balance. The teeth were positioned in the opening of the glass vials and supported by putty material to create a hermetic seal. A 27-G needle was placed alongside the stopper to balance the air pressure inside and outside the tube.

To avoid variation and to eliminate biases, the cleaning, shaping, and irrigation of all the samples were completed by the same operator. Rubber dam sheets were used to cover the vials to prevent the operator from viewing debris and irrigant extrusion during the canal preparation phase. All files used in this study were set into motion with a X-Smart Plus contra angle 6:1 reduction handpiece and speed 350 (Dentsply/Maillefer,Tulsa,USA).

Table 1: Amount of apically extruded debris (gram) after the use of different instruments.

\begin{tabular}{|l|l|l|l|l|l|}
\hline \multirow{2}{*}{ Group } & \multirow{2}{*}{$\mathbf{n}$} & \multicolumn{3}{|l|}{$\begin{array}{l}\text { Amount of apically extracted } \\
\text { debris (gm) }\end{array}$} & \multirow{2}{*}{ t (P) } \\
\cline { 3 - 5 } & & $\begin{array}{l}\text { Mean } \\
\text { (SD) }\end{array}$ & Minimum & Maximum & \\
\hline $\begin{array}{l}\text { One } \\
\text { shape } \\
\begin{array}{l}\text { Revo- } \\
\text { S }\end{array}\end{array}$ & 18 & $\begin{array}{l}0.0014 \\
(0.0003)\end{array}$ & 0.0009 & 0.0020 & 13.2 \\
& 18 & $\begin{array}{l}0.0040 \\
(0.0008)\end{array}$ & 0.0029 & 0.0056 & $(0.001)^{*}$ \\
\hline
\end{tabular}

SD: Standard Deviation.

$\mathrm{t}$ : independent sample t-test.

$* \mathrm{P}<0.05$ (significant)

An Endo flare (Micro-Mega, Cedex, Besancon, France) was used and was limited to three $\mathrm{mm}$ into the canal. A small number $15 \mathrm{~K}$-file was used in slight pecking motion until the working length was achieved.

Bi-distilled water was used as the irrigation solution. In each sample, a total of $6 \mathrm{~mL}$ of bi-distilled water was used. A 27-G irrigation needle was used. Irrigation was performed in exactly the same manner for all the specimens. After every file motion, the files were with-drawn from the canals, the flutes were cleaned, and the root canals were irrigated by two $\mathrm{mL}$ bi-distilled water.

After instrumentation was completed, the stopper, needle and the tooth were separated from the vials. The debris adhering to the root surface was collected by washing the root with one $\mathrm{ml}$ of bi-distilled water in the vials. Each vial was weighed to determine the amount of debris and irrigant extruded into the peri-apical area. The vials were then placed in a dry-heat oven at $110 \mathrm{c}$ and were checked every half an hour until the vials appeared dry. The vials were then weighed using the same analytical balance to obtain the final weight of the tubes, including the extruded debris. The weight of the empty vials was subtracted from the weight of the vials containing the debris, and the dry weight of the extruded debris was calculated for each group. The weight of the irrigant was calculated by subtracting the weight of the vial and the weight of the dry debris from the weight of the vial containing the irrigant and debris.

The present study was performed after receiving the approval of the Research Ethics Committee in the Faculty of Dentistry, Alexandria University.

\section{STATISTICAL ANALYSIS:}

After data were collected it was revised, coded and fed to statistical software SPSS IBM version 22. The given graphs were constructed using Microsoft excel software. All statistical analysis was done using two tailed tests and alpha error of 0.05 . After data management and validation, amount of extracted debris and amount of irrigant were calculated for each group using simple mathematical extraction methods.

The following statistical tests were used: Descriptive statistics in the form of frequencies and percent were used to describe the categorical data (no of units per group) all other parameters were expressed as mean (SD) and range (Min-Max). To test for differences between average amount of irrigant or debris and also at crude weights between the two groups, independent samples t-test was used for data following normal distribution.

\section{RESULTS:}

The amount of extruded debris was recorded for both groups. It was found that One shape file extruded significantly less amount of debris than Revo-S system. The mean values, minimum, maximum, and standard deviations for debris are illustrated in table 1.

The amount of extruded irrigant was recorded for both groups. It was found that One shape file extruded significantly less amount of irrigant than Revo-S system. The mean values, minimum, maximum, and standard deviations for irrigant are illustrated in table 2 .

\section{DISCUSSION:}

Over the years, apical extrusion of intracanal materials has been investigated in many studies because of its clinical relevance (2-4).

Apical extrusion of irrigation solution as well as intracanal debris can accidently extrude into the periapical area. These two components were responsible for postoperative flare-ups (1).

Therefore, the main objective of this study was to evaluate the apical extrusion of debris and irrigant as a result of root canal preparation by different instrumentation systems.

A variety of NiTi instruments have evolved all aiming at improving over the limitations presented in earlier systems. Because the canal preparation with rotary nickel-titanium systems remains significantly more centered in the root canal, there is less transport of materials than hand filing with stainless steel files (8). The recently introduced One shape NiTi instrument was selected in this study to see its effect on debris and irrigant extrusion in comparison to the full sequence Revo-S which uses three files. The single file system has broken some paradigms related to root canal preparation. Unlike other instruments, One shape file does not require a sequential enlargement of the canal with different files of varying size and taper. Only one file is 
sufficient for entire enlargement of the root canal to a desired canal shape and size. In addition, providing a glide path with smaller files is not mandatory with these files, hence reflecting a paradigm shift. In the present study the endoflare was used in both systems aiming to standardization.

Table 2: Amount of apically extruded irrigant (mililiter) after the use of different instruments.

\begin{tabular}{|l|l|l|l|l|l|}
\hline \multirow{2}{*}{ Group } & \multirow{2}{*}{$\mathbf{n}$} & \multicolumn{3}{|l|}{$\begin{array}{l}\text { Amount of apically extracted } \\
\text { Irrigant (m) }\end{array}$} & \multirow{2}{*}{ (P) } \\
\cline { 3 - 5 } & & $\begin{array}{l}\text { Mean } \\
\text { (SD) }\end{array}$ & Minimum & Maximum & \\
\hline One shape & 18 & $\begin{array}{l}1.32 \\
(0.24)\end{array}$ & 0.93 & 1.93 & \\
Revo-S & 18 & $\begin{array}{l}1.82 \\
(0.49)\end{array}$ & 1.02 & 2.96 & $\begin{array}{l}3.8 \\
(0.001)^{*}\end{array}$ \\
\hline
\end{tabular}
0.05 (significant)

The One shape file was used to prepare only one canal before it was discarded whereas the Revo-S files were used to prepare three canals before it was discarded to simulate the clinical condition. Both files used the crown down technique in rotation motion.

With the clear purpose of approximating the challenging clinical situation, distobuccal canals of extracted upper first molars with curvature more than $10 \&$ less than 25 degree according to Schneider (9) technique, were utilized for this study. Parallel to the present study Sumer and Akpinar 2005 (12) and Tanalp et al 2006 (10) used extracted human teeth as they were found to be better than acrylic models (11) for their clinical relevance by reproducing dentin characteristics where as in acrylic models acryl was removed rather than dentin, which might affect instrument efficiency due to clogging of acryl on the files flutes. Also canal curvature, length and presence of more than one canal are other factors that may affect the final amount of apical extrusion (6). This was found in accordance with De-Deus et al 2010 (13) who used mesial roots of lower molars. Though in the majority of the previous studies single canals were used, as Myers and Montgomery 1991 (7) used singlerooted maxillary lateral incisors and mandibular premolars, Reddy and Hicks 1998 (2) used single-rooted mandibular premolar teeth, Ferraz et al 2001 (3) used maxillary and mandibular central and lateral incisors with single canals, and Lambrianidis et al 2001 (14) used maxillary central and lateral incisors. Usually single rooted teeth were used because of the ease in set up of the collector apparatus $(6,15,16)$. De- Deus et al 2010 (13) reported that preparation of single-rooted teeth tends to extrude less debris, because the cleaning and shaping procedures are easier and more predictable.

Teeth used in this study were carefully selected to have mature root morphology, as results may completely change with teeth in which apical closure has not occurred (17). In this work the apical foramen size was standardized in which \#15, stainless steel K-file could snugly fit at the foramen. Tinaz et al 2005 (15) stated that variation in apical foramen size between the specimens would actually affect the amount of apically extruded debris and irrigant. However, Fairbourn et al 1987 (21), McKendry 1990 (17), and AlOmari and Dummer 1995 (18), found no significant correlation between apical diameter and amount of extruded debris.

As the average length of the upper first molar is $20.5 \mathrm{~mm}$, and in the clinical situation the crown acted as a reservoir for the irrigation solution, but in the present study since it was a laboratory study the distal roots were sectioned and reduced to $15 \mathrm{~mm}$ to achieve standardization of irrigant, provide a reproducible and definite reference point for measurement of the working length, simplify handling of the specimen, allow better visualization of root canal morphology and eliminate any coronal interference's during canal preparation.

Nail varnish was used to cover the root to prevent the exit of debris and irrigant from accessory canal and this was found to be followed by Ferraz et al 2001 (3), while McKendry 1990 (17) and Tasdemir T et al 2010 (20) ignored this point.

In this study instrumentation was confined to $1 \mathrm{~mm}$ short of the apical foramen (16) because working length $1 \mathrm{~mm}$ short of the canal length contributed to significantly less debris extrusion (7,21). Whereas, Martin and Cunningham (23) demonstrated greater debris extrusion when canals were instrumented at a length were the file was observed to just protrude through the apical foramen versus 1-mm short of the foramen. Many practitioners prefer the working length to be $0.5 \mathrm{~mm}$ short of the canal length, under such conditions it may be speculated that the quantity of debris extruded would be even greater than canals prepared $1 \mathrm{~mm}$ short of the apex.

The type of irrigant plays an important role on the amount of apically extruded debris and irrigant. In this study Bidistilled water was used as an irrigation solution as done by Al-Omari et al 1995 (18) and Beeson et al 1998 (24) to avoid any possible weight increase due to crystallization of sodium hypochlorite after drying. Since dryness of the $\mathrm{NaOCl}$ irrigant resulted in salt crystals which cannot be separated from the cutting debris, leading to discrepancy in data collection (22), as the study done by McKendry et al (17) that used $2.5 \% \mathrm{NaOCl}$ and Tinaz et al 2005 (15) that used 2.6\% NaOCl. Their idea was based on; irrigation was a necessary and important phase of cleansing the canal. The irrigation functions as a lavage, a solvent, a disinfectant, and a lubricant within the canal. Even though mineral salts precipitated after evaporation of $\mathrm{NaOCl}$ and could affect the results, but they could not be neglected as part of the extruded debris and should be taken in consideration, as the amount of extruded debris not the amount of extruded dentin should be measured.

Aiming at standardization of the amount of irrigating solution, all specimens were irrigated with a total of six ml employing a 27 gauge needle with a bent tip, the amount of irrigation solution was kept constant in both groups to decrease variables during the irrigation process. The needle was never wedged in the canal, and lied passively in the canal, without engaging the walls and the solution was introduced slowly. This method would minimize forcing the irrigant out of the canal (25). The depth of needle tip placement is an important factor in root canal irrigation. It has been recommended to place the needle tip to two $\mathrm{mm}$ short of the working length or slightly coronal to that point when resistance is encountered before the needle tip reaches the desirable distance (26). Therefore, in the present study the same needle penetration depth was used. The canals were fully prepared by incremental crown-down 
instrumentation by dividing the canal into a coronal two thirds followed by three $\mathrm{mm}$ from the working length followed by preparation to the full working length, to provide more standardization of the methodology.

In the present study, the generally accepted method of Myers and Montgomery (7), which is more standardized and repeatable than other methods, was used to collect the intra-canal materials (27). Unlike Liu et al 2013 (27) and Burklein et al 2014 (1) and that used different techniques to measure the apically extruded debris and irrigant.

In the present study, both systems showed extrusion of irrigant and debris, meanwhile the One shape system showed significantly less extrusion of irrigant and debris than the Revo-S system.

A common finding has been that all instrumentation techniques produce apical extrusion to a certain extent (25). However, the One shape single-file system extruded less debris than the Revo-S full sequence rotary system. This might be due to the innovative instrument design of the One shape file that has a variable cross-section with three different cross-section zones. The first zone presents a variable three cutting edge design, the second prior to the transition has a cross section that progressively changes from three to two cutting edges, and the last (coronal) is provided with two cutting edges this observation was found to be in agreement with Nayak et al 2014 (28). While the Revo-S files have an asymmetrical cross-section, the canal axis has three cutting edges located on three different radii. This special design of the One shape file might contribute to the better coronal debris elimination.

The variations recorded in terms of weight of debris and irrigant extruded might be also attributed to that the One shape file $6 \%$ taper prepared the entire canal with a single file, though the instrumentation of the canal was done in an incremental crown down preparation of the coronal two thirds first followed by a three $\mathrm{mm}$ increase in depth ending by preparation of the entire length of the canal apically. The close and intimate contact of the canal walls with a single file in continuous rotation may have produced a decrease in debris extrusion, meanwhile in the Revo-S system the canals were first prepared by Sc1 6\% taper that prepared the coronal two thirds followed by Sc2 4\% taper which prepared the canal to the full working length, enlarging it to some extent before using the Su $6 \%$ taper thus loosing the previously mentioned intimate contact between the file and the canal walls.

The results of this study were in accordance to the study conducted by Kucukilmaz et al 2015 (29) who stated that the single file One shape extruded less debris than the full sequence Protaper.

Furthermore, the use of three files in the Revo-S system versus one file in the One shape system may explain why the higher amount of apically extruded debris and irrigant was found in the Revo-S system than the One shape system. This was found to be in agreement with Tanalp et al (10) who mentioned that increasing number of instruments may increase the amount of apical debris extrusion.

It was also reported by Nayak et al 2014 (28) that One shape instrumentation technique using a full rotation motion extruded less debris than reciprocating files as Wave one and Reciproc, as the reciprocating and in-and-out filing motion, may act as a piston, extruding more debris and irrigant than One shape. While the file with continuous rotation act like a screw conveyor improving transportation of dentin chips and debris coronally (16). Adl et al (5) suggested that reduction of debris extrusion in rotary preparation techniques is not due to crown down technique but rather related to rotational motion of files. A probable explanation for this finding is that rotary motion tends to pull dentinal debris in to the flutes of the file and direct it toward the coronal aspect of the canal $(19,24,30)$. Ruddle 2012 (30), concluded that continuous rotation required less inward pressure and improved the capacity to auger the debris out of the canal.

It was reported by Vande Visse \& Brilliant (1975) (31) that canal instrumentation without irrigant did not produce collectible amount of debris; however a collectible amount of debris was extruded when an irrigant was used.

The One shape file produced significantly less amount of irrigant in comparison to Revo-S system; this might be due to the use of a single file in comparison to full sequence file set. Unlike another study conducted by Yeter et al 2013 (32) which didn't agree with this finding, this maybe because they used size 25 gauge needle and we used size 27. Also the type of needle affects the amount of irrigant. The needle used in this study is the open-ended needle. The double side-port needles extruded significantly less irrigant than the open-ended needles (32). Furthermore, this was also in agreement with Altundasar et al 2011(33) who compared regular and double side-port needles in a recent laboratory study. Nayak et al 2014 (28) also proved that the syringe type also affects the amount of irrigant extrusion; the mononjet irrigating syringe with 30 gauge side-port opening needle minimized forcing irrigant out of the canal.

To the best of our knowledge, although there have been similar studies in the literature, only few studies compared the amount of extrusion of irrigant and no studies have compared the extrusion of both apical debris and irrigation solution by One shape single file system and Revo-S full sequence rotary systems.

The obtained differences between the instruments might have been caused by many factors such as instrument size, type, cross-sectional design, canal preparation technique and endpoint, apical stop, irrigation solution, and irrigation delivery system play an important role in affecting the amount of debris and irrigant extrusion $(3,15,33)$. In the present study to minimize the effect of the aforementioned factors, standard conditions were created.

The apical third of the canal has been reached in the Revo-S system by two files $\mathrm{Sc} 2$ and $\mathrm{Su}$ while in the One shape system it was reached by one file, this may have produced a sort of disturbance in the apical plug formed leading to the fore mentioned increase of debris and irrigant extrusion. If apical plugs are formed, it is likely that the amount of debris and irrigants extruded would be far less than observed otherwise. In addition, apical plug formation would also prevent over instrumentation and extrusion of filling materials.

Though great care was taken to standardize the experimental groups and procedures, it must be emphasized that the results of this study should not be directly extrapolated to the clinical histopathological study conducted by Bidar et al 2005 (34), no significant correlation in periapical inflammation following preparation of the root canal with conventional and rotary instrumentation was found. But Bonaccorso et al 2009 (35) in an in vivo model, found that the presence of periapical tissues serves as a natural barrier providing a physical back 
pressure thereby limiting the apical extrusion of debris and irrigant . While Altundasar et al 2011 (33) suggested to use floral foam to simulate resistance offered by periapical tissues; in this study no such attempt was made. Because of the lack of back pressure in this study, gravity may have played an important role in carrying the irrigant out of the canal. Besides, in a clinical setting, a positive or a negative pressure at the apex associated with normal or pathological peri-apical tissues plays an important role in determining the extent to which debris and irrigants extrude peri-apically (36). Chemo-mechanical instrumentation of vital and necrotic teeth also plays an influential role in apical extrusion. In an in vivo study, Salzgeber and Brilliant 1977 (37) found that in vital teeth, pulp tissue present apically and in lateral canals prevented extrusion of the irrigant out of the root canal. In cases of necrosis, the solution disperses when it reaches the apical region situation.

\section{CONCLUSION:}

Based on the results of the study, both single file system and the multiple file system produced apical extrusion of debris and irrigant. It may be necessary to find instruments and techniques that would minimize the extrusion of such elements to reduce the incidence of flare-ups in endodontics.

\section{CONFLICT OF INTEREST:}

The authors declare that they have no conflict of interest.

\section{REFERENCES:}

1. Bürklein S, Benten S, Schäfer E. Quantitative evaluation of apically extruded debris with different single-file systems: Reciproc, F360, and OneShape versus Mtwo. Int Endod J. 2014;47:405-9.

2. Reddy SA, Hicks ML. Apical extrusion of debris using two hand and two rotary instrumentation techniques. J Endod. 1998;24:180-3.

3. Ferraz CCR, Gomes NV, Gomes BPFA, Zaia AA, Teixeira FB, Souza-Filho FB. Apical extrusion of debris and irrigants using two hand and three engine-driven instrumentation techniques. J Endodon. 2001;34:354-8.

4. Albrecht LJ, Baumgartner JC, Marshall JG. Evaluation of apical debris removal using various sizes and tapers of ProFile GT files. J Endod. 2004;30:425-8.

5. Adl A, Sahebi S, Moazami F, Niknam M. Comparison of apical debris extrusion using a conventional and two rotary techniques. Iran Endod J. 2009;4:135-8.

6. Bidar M, Rastegar AF, Ghaziani P, Namazikhah MS. Evaluation of apically extruded debris in conventional and rotary instrumentation techniques. J Calif Dent Assoc. 2004;32:665-7.

7. Myers GL, Montgomery S. A comparison of weights of debris extruded apically by conventional filing and canal master techniques. J Endod. 1991; 17:275-9.

8. Lopez FU, Fachin EV, Camargo Fontanella VR, Barletta FB, So MV, Grecca FS. Apical transportation: a comparative evaluation of three root canal instrumentation techniques with three different apical diameters. J Endod. 2008;34:15458 .

9. Schneider SW. A comparison of canal preparations in straight and curved root canals. Oral Surg Oral Med Oral Pathol. 1971;32:271-5.

10. Tanalp J, Kaptan F, Sert S, Kayahan B, Bayirl G. Quantitative evaluation of the amount of apically extruded debris. Using 3 different rotary instrumentation systems. Oral Surg Oral Med Oral Pathol Oral Rad Endod. 2006;101:252-9.

11. Ruiz-Hubard EE, Gutmann JL, Wagner MJ. A quantitative assessment of canal debris forced periapically during root canal instrumentation using two different techniques. J Endod. 1987;13:554-8.

12. Er K, Sümer Z, Akpinar KE. Apical extrusion of intracanal bacteria following use of two enginedriven instrumentation techniques. Int Endod J. 2005;38:871-6.

13. De-Deus G, Brandao MC, Barino B, Giorgi KD, Fidel RAS, Luna AS. Assessment of apically extruded debris produced by the single file Protaper techniq ue under reciprocating movement. J Endodon. 2010;110:390-4.

14. Lambrianidis T, Tosounidou E, Tzoanopoulou M. The effect of maintaining apical patency on periapical extrusion. J Endod. 2001;27:696-8.

15. Tinaz AC, Alacam T, Uzun O, Maden M, Kayoglu $\mathrm{G}$. The effect of disruption of apical constriction periapical extrusion. J Endod. 2005;31:533-5.

16. Burklein S, Schafer E. Apically extruded debris with reciprocating single file and full sequence rotary instrumentation systems. $\mathrm{J}$ Endodon. 2012;38:850-2.

17. McKendry DJ. Comparison of balanced forces, endosonic and stepback filing instrumentation techniques: quantification of extruded apical debris. J Endodon. 1990;16:24-7.

18. Al-Omari MA, Dummer PMH. Canal blockage and debris extrusion with eight preparation techniques. J Endod. 1995;21:154-8.

19. Kustarci A, Akdemir N, Siso SH, Altunbas D. Apical extrusion of intracanal debris using two engine driven and step-back instrumentation techniques: an invitro study. Eur J Dent. 2008;2:233-9.

20. Tasdemir T, Er K, Celik D, Aydemir H. An in vitro comparison of apically extruded debris using three rotary nickeltitanium instruments. JDS. 2010;5:121-5.

21. Fairboun DR, McWalter GM, Montgomery S. The effect of four prepa- ration techniques on the amount of apically extruded debris. J Endod. 1987; $13: 102-8$

22. Hamouda MMG, Tawfik HMEE, Abou-Elezz AF, Ibrahim DY. Effect of apical patency apically extruded debris during canal enlargement using hand or rotary instruments. J Am Sci. 2011;7:33-7.

23. Martin H, Cunningham WT. The effect of endosonic and hand manipulation on the amount of root canal material extruded. Oral Surg. 1982;53:611-3.

24. Beeson TJ, Hartwell GR, Thornton JD, Gunsolley JC. Comparison of debris extruded apically in 
straight canals: Conventional filing versus Profile 0.04 Taper Series 29. J Endod. 1998;24:18-22.

25. Boutsioukis $\mathrm{C}$, Verhaagen $\mathrm{B}$, Versluis $\mathrm{M}$, Kastrinakis E, Wesselink PR, van der Sluis LW. Evaluation of irrigant flow in the root canal using different needle types by an unsteady computational fluid dynamics model. J Endod. 2010;36:875-9.

26. Retamozo B, Johnson N, Aprecio RM, Torabinejad M. Minimum contact time and concentration of sodium hypochlorite required to eliminate Enterococcus faecalis. J Endod. 2010;36:520-3.

27. Liu R, Hou BX, Wesselink PR, Wu MK, Shemesh $\mathrm{H}$. The incidence of root microcracks caused by 3 different single-file systems versus the ProTaper system. J Endod. 2013;39:1054-6.

28. Nayak G, Singh I, Shetty SH, Dahiya S. Evaluation of apical extrusion of debris and irrigant using two new reciprocating and one continuous rotation single file system. J Dent (Tehran). 2014;11:302-9.

29. Kucukyilmaz E, Savas S, Saygili G, Uysal B. Assessment of apically extruded debris and irrigant produced by different nickel-titanium instrument systems. Braz Oral Res. 2015;29:1-6.

30. Ruddle CJ. Endodontic canal preparation: WaveOne single-file technique. Dent Today. 2012;31:1-7.

31. Vande Visse JE, Brilliant JD. Effect of the irrigation on the production of extruded material at the root apex during instrumentation. J Endod. 1975;1:2436.

32. Yeter KY, Evcil MS, Ayranci LB, Ersoy I. Weight of apically extruded debris following use of two canal instrumentation techniques and two designs of irrigation needles. Int Endod J. 2013;46:795-9.

33. Altundasar E, Nagas E, Uyanik O, Serper A. Debris and irrigant extrusion potential of 2 rotary systems and irrigation needles. Oral Surg Oral Med Oral Pathol Oral Radiol Endod. 2011;112:31-5.

34. Bidar M, Moradi S, Zarrabi MH, Barikbin B. Histopathological Study of Periapical Inflammation Following Preparation of the Root Canal with Conventional and Profile Rotary Instrumentation in Teeth of Cats. J Dent (Tehran) 2005;2:7-12.

35. Bonaccorso A, Cantatore G, Condorelli GG, Schäfer E, Tripi TR. Shaping ability of four nickeltitanium rotary instruments in simulated S-shaped canals. J Endod. 2009;35:883-6.

36. Mohorn HW, Dowson J, Blankenship JR. Odontic periapical pressure following vital pulp extirpation. Oral Surg Oral Med Oral Pathol. 1971;31:536-44.

37. Salzgeber RM, Brilliant JD. An in vivo evaluation of the penetration of an irrigating solution in root canals. J Endod. 1977;3:394-8. 